\title{
AN ONLINE INTERACTIVE COMPETITION MODEL FOR E-LEARNING SYSTEM
}

\author{
P. C. Ezenkwu ${ }^{1, *}$, C. Aneke ${ }^{2}$ and K. I. Akpabio ${ }^{3}$ \\ 1, 2, 3 Dept. of Electrical/Electronic ANd Computer Engr., Univ. of Uyo, Uyo, AKWA Ibom STATe, NigERIA \\ Email addresses: 1chineduezenkwu@uniuyo.edu.ng, ${ }^{2}$ neketonbc@yahoo.com,3hitey2000@yahoo.com
}

\begin{abstract}
This paper presents an Online Interactive Competition Model for E-learning System. The system allows a student to connect and interact with other students on the courses they offer in a semester using both synchronous and asynchronous computer-mediated communication mechanisms. Each course lecturer e-supervises and e-moderates the students' performances in his/her course. Following the semester course outlines, the system automatically and periodically selects topics for discussions. Each student's questions as well as his/her contributions to questions posed by other students or even the lecturers on the e-learning platform are rated by the course lecturers who equally make their contributions in difficult cases. On registration, a student is assigned the rank of a starter in all courses. Based on a course lecturer's ratings on a student and how long the student had used the course page, the student may rise to the following ranks in the course: Senior, Master, Expert or Professional. In this paper, the scalable algorithm for the students' ranking is presented. Moreover, a student's ranks in different courses are independent; that is, a student can be an expert in one course and a starter in another. This ranking strategy serves as an incentive to encourage the students to participate actively and make meaningful contributions to questions posted on the platform. A working prototype of the system was developed using MySQL Database Management System (DBMS), PHP as the scripting language and Apache as the web server. The system was tested and the results were presented graphically in this paper.
\end{abstract}

Keywords: competition, online, ranking, e-learning, social network, social e-learning, algorithm

\section{INTRODUCTION}

The mind-boggling rate at which Information and Communication Technology (ICT) permeates every section of society has encouraged the adoption of ICT in virtually all areas of human endeavour. Nowadays, mobile technologies, social networks, and internet services are ubiquitous and at budget prices. Due to the foregoing, the rate at which people use and share information via social networks has considerably burgeoned. Interestingly, most available social network sites provide group-centred social services in addition to the usual individual-centred social services. These group-centred social services encourage the formation of online communities tailored to foster groups' interests, ideas, opinions and objectives. Consequently, the integration of social networking capabilities into e-learning systems, formally known as social e-learning, has gained momentum recently. This has encouraged the incorporation of discussion forums where the users of an e-learning information system, both the teachers and the students, can share ideas amongst themselves. Subsequently, e-learning has become more interesting, less boring, thus leading to relatively larger participation of students and teachers. Unarguably, experts in psychology, sociology and other related disciplines have massively supported humans' proclivity to compete with one another. Although, some disadvantages associated with humans' competition with one another have been identified, yet, experts in education have corroborated the importance of classroom competition among learners. Observably, one of such importance of classroom competitions is that it encourages efficient learning and effective participation of the learners in the learning activities. However, the attempts to incorporate similar competition obtainable in offline classrooms into elearning forums have been inadequate. Motivated by the foregoing, this paper seeks to present an Online 
Interactive Competition Model for E-learning System .The thrust of the research is the integration of a competition strategy into a social e-learning system in order to activate a sort of incentive that will encourage users' attraction and active participations on the system. This system allows the students to visualise and participate in the courses they offer in a semester. The topics in the courses' outlines are periodically selected and made available to the students for discussions. On registration, a student is assigned the rank of a starter and afterwards, depending on how often the student uses the system and his/her contributions to questions posed by other students and even the course lecturer, the student may earn higher ranks such as Senior, Master, Expert and Professional. Moreover, the ranks of each student in different courses on the platform are uncorrelated and hence, a student can be at different ranks in different courses. Moreover, lecturers as well as the students can search and visualise any student's progress in a course on the system. A prototype of this system is developed following a user-centred software development methodology.

\section{REVIEW OF RELATED LITERATURE}

Over the last few decades, the quality of education in Nigeria has continued to decline, leading to growing population of unemployable graduates and increasing incidence of functional illiteracy across the nation [1]. One of the most effective solutions to this challenge is the adaptation of academic activities to modern day technologies. According to [2], Information Technology (IT) is a pivot of new phase lift to educational system. It has reformed the mode of learning on the part of learners from passiveness to activeness that promote mental reform and skills [2]. The ubiquity of social media such as facebook, twitter, LinkedIn, Google+, MySpace, Flickr etc has to a great extent encouraged collaboration and information sharing among people [3]. Social E-learning can be defined as incorporating elearning into a social network such that the tools available in the social network for interconnectivity and interactivity can be used to enhance teaching and learning processes [1]. Considering activities such as sports, economics, politics, school and so on, it is evident that competition is deeply rooted in human evolutionary heritage. According to [4] "human competition is a contest where two or more people strive for a goal that cannot be shared, usually resulting in a victor and a loser. Individuals and/or groups are then in a position where they must vie for the achievement of an outcome. Competition remains a powerful instinctual drive in human nature". [5] opined that "one of the best ways to let students to be actively involved in class would be to introduce classroom competitions. Classroom competitions have been motivating and promoting students to work harder." Furthermore, [6] show that a competitive element acts as an incentive for all students to put in more effort and even weaker students persist with participating in class activity. Nowadays, people, especially the young ones are more inclined to the use of Information and Communication Technologies (ICT) than the older people. Young people see technologies (and especially the internet) as a vital part of their social life and the building of their identity [7]. According to [8], " the pedagogical and socio-economic forces that have driven the higher learning institutions to adopt and incorporate ICTs in teaching and learning include greater information access; greater communication; synchronous and asynchronous learning; increased cooperation and collaboration, cost-effectiveness and pedagogical improvement. “

\section{METHODOLOGY}

The system development begins with an effective usercentred requirement engineering approach. The requirement engineering process model is presented in fig. 1. The activities involved include; feasibility study, requirement elicitation, requirement analysis and requirement validation. The outcomes of these activities are feasibility report, system's/users' requirements, triangulated requirements and the requirement specification respectively. Each of the outcomes is available to the system stakeholders for feedbacks to the system developer or researcher. The developer can as well consult experts and consultants for better clarifications.

\subsection{System Modules}

The system design follows a top-down design approach. The top-down design architecture of the system showing the system modules and sub-systems is presented in fig. 2. The System modules include:

a). General System Module

i. The Registration sub-module

ii. Login sub-module

iii. User Feedback sub-module

iv. Help-Desk

b). Student Module

i. Course Selection sub-module

ii. Course Discussion sub-module 
iii. Student progress sub-module

c). Course Lecturer Module

i. Course Discussion sub-module

ii. Students' contributions rating sub-module

iii. Students' progress sub-module

\subsection{Algorithm for Students' Ranking}

The ranking parameters are defined as follows:

$\mathrm{S}_{\mathrm{s}}$ is the Minimum score required for a user to attain the level of a senior, $\mathrm{T}_{\mathrm{s}}$ is the Minimum time required for a user to attain the level of a senior, $S_{m}$ is the Minimum score above which a user to attain the level of a master $\mathrm{T}_{\mathrm{m}}$ is the Minimum time required for a user to attain the level of a master, $\mathrm{S}_{\mathrm{e}}$ is the Minimum score required for a user to attain the level of an expert, $\mathrm{T}_{\mathrm{e}}$ is the Minimum time required for a user to attain the level of an expert $\mathrm{S}_{\mathrm{p}}$ is the Minimum score required for a user to attain the level of a professional, $\mathrm{T}_{\mathrm{p}}$ is the Minimum time required for a user to attain the level of a professional, $S_{u}$ is the Total score of a user on a course page, $\mathrm{T}_{\mathrm{u}}$ is the Total time spent by a user on a course page and $R_{u}$ is the Current Rank of a user on a course.

Initialise $\mathrm{S}_{\mathrm{u}}$

Initialise $\mathrm{T}_{\mathrm{u}}$

Initialise $\mathrm{R}_{\mathrm{u}}$

Set the values of $S_{s}, S_{m}, S_{e}, S_{p}, T_{s}, T_{m}, T_{p}$

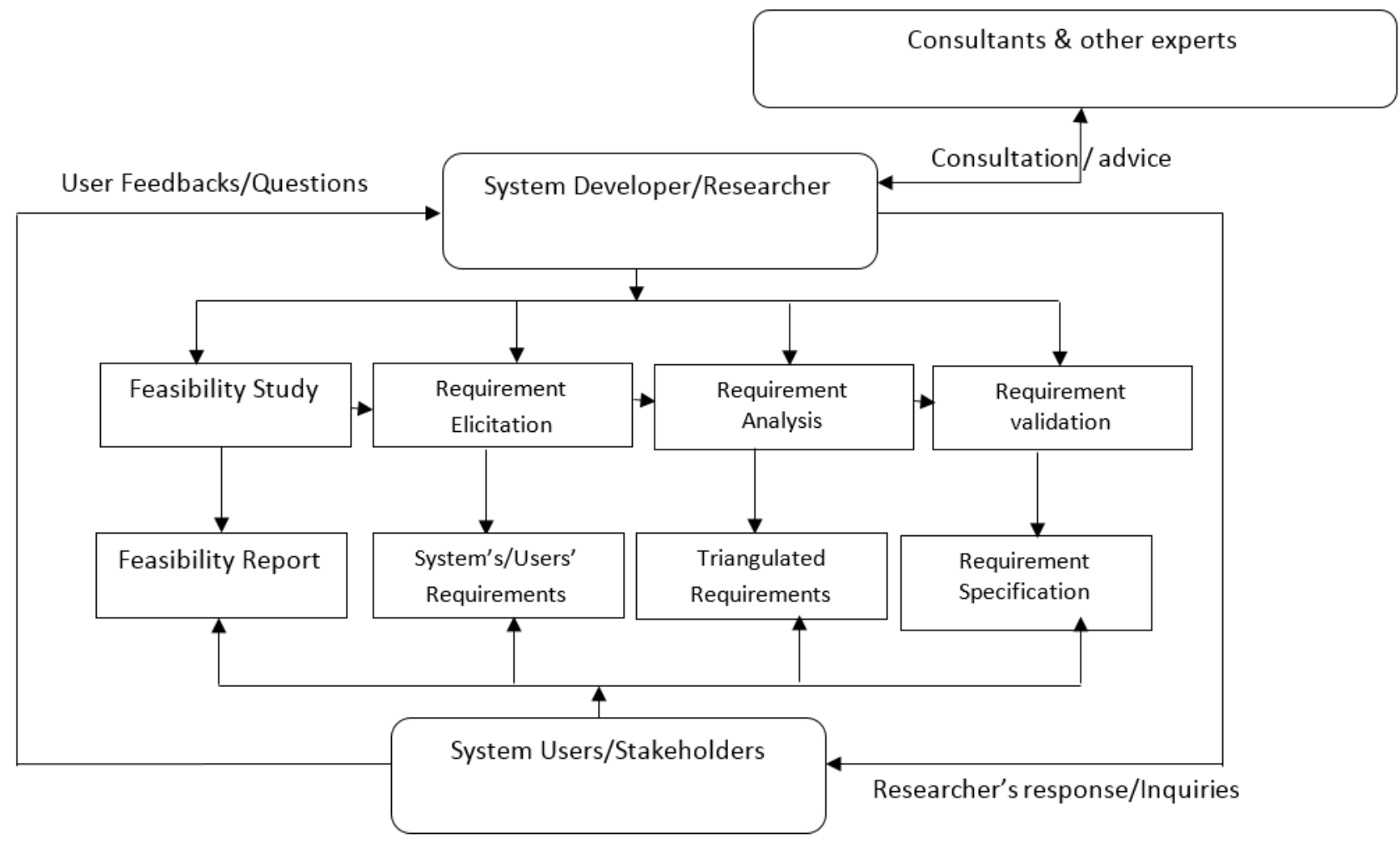

Fig. 1: A User-centred Requirement Engineering Process Model

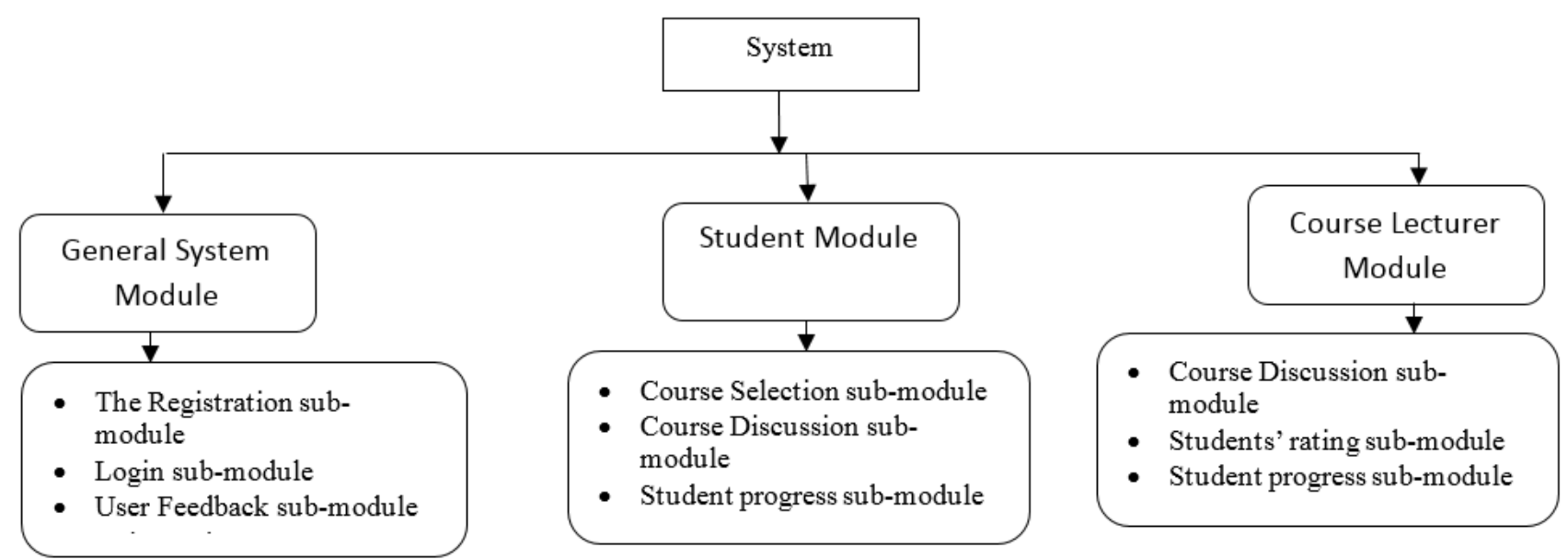

Fig.2: The top-down design architecture of the system 
BEGIN (obtain the updated values of $S_{u}, T_{u}$ to compute current $R_{u}$ )

$$
\begin{aligned}
& \text { if }\left(\mathrm{S}_{\mathrm{u}}-\mathrm{S}_{\mathrm{s}}\right) /\left(1+\left|\mathrm{S}_{\mathrm{u}}-\mathrm{S}_{\mathrm{s}}\right|\right) * \mathrm{~T}_{\mathrm{u}}<\mathrm{T}_{\mathrm{s}} \\
& \mathrm{R}_{\mathrm{u}} \leftarrow \text { 'starter' } \\
& \text { else if }\left(\mathrm{S}_{\mathrm{u}}-\mathrm{S}_{\mathrm{s}}\right) /\left(1+\left|\mathrm{S}_{\mathrm{u}}-\mathrm{S}_{\mathrm{s}}\right|\right)^{*} \mathrm{~T}_{\mathrm{u}}>\mathrm{T}_{\mathrm{s}} \& \&\left(\mathrm{~S}_{\mathrm{u}}-\mathrm{S}_{\mathrm{m}}\right) /\left(1+\left|\mathrm{S}_{\mathrm{u}}-\mathrm{S}_{\mathrm{m}}\right|\right)^{*} \mathrm{~T}_{\mathrm{u}}<\mathrm{T}_{\mathrm{m}} \\
& \mathrm{R}_{\mathrm{u}} \leftarrow \text { 'Senior' } \\
& \text { else if }\left(\mathrm{S}_{\mathrm{u}}-\mathrm{S}_{\mathrm{m}}\right) /\left(1+\left|\mathrm{S}_{\mathrm{u}}-\mathrm{S}_{\mathrm{m}}\right|\right) * \mathrm{~T}_{\mathrm{u}}>\mathrm{T}_{\mathrm{m}} \& \&\left(\mathrm{~S}_{\mathrm{u}}-\mathrm{S}_{\mathrm{e}}\right) /\left(1+\left|\mathrm{S}_{\mathrm{u}}-\mathrm{S}_{\mathrm{e}}\right|\right) * \mathrm{~T}_{\mathrm{u}}<\mathrm{T}_{\mathrm{e}} \\
& \mathrm{R}_{\mathrm{u}} \leftarrow \text { 'Master' } \\
& \text { else if }\left(\mathrm{S}_{\mathrm{u}}-\mathrm{S}_{\mathrm{e}}\right) /\left(1+\left|\mathrm{S}_{\mathrm{u}}-\mathrm{S}_{\mathrm{e}}\right|\right) * \mathrm{~T}_{\mathrm{u}}>\mathrm{T}_{\mathrm{e}} \& \&\left(\mathrm{~S}_{\mathrm{u}}-\mathrm{S}_{\mathrm{p}}\right) /\left(1+\left|\mathrm{S}_{\mathrm{u}}-\mathrm{S}_{\mathrm{p}}\right|\right) * \mathrm{~T}_{\mathrm{u}}<\mathrm{T}_{\not 2} \\
& \mathrm{R}_{\mathrm{u}} \leftarrow \text { 'Expert' } \\
& \text { else if }\left(S_{u}-S_{p}\right) /\left(1+\left|S_{u}-S_{p}\right|\right) * T_{u}>T_{p} \\
& \mathrm{R}_{\mathrm{u}} \leftarrow \text { 'Prof }
\end{aligned}
$$

END

\&\& stands for logical AND

\subsection{Students Activities Flowchart}

The activities of a student in the system are shown in the flowchart of fig.3. On registration, a student is assigned the rank of a starter in all courses. The student can access all the courses he/she offers in a semester. As soon as a student selects any particular course for discussion, the course login time, $t_{i}$ is recorded and the time the student logs out from the course page, $t_{o}$ is equally recorded. With the following parameters, the total time spent by the student, $\mathrm{T}_{\mathrm{u}}$ on the course discussion page is updated by; new $\mathrm{T}_{\mathrm{u}}=$ old $\mathrm{T}_{\mathrm{u}}+\Delta t$ tand $\Delta t=t_{o}-t_{i}$. Furthermore, the student's rating scores from the lecturer for any new session is assigned to the previous total score in order to obtain the current total score, $\mathrm{s}_{\mathrm{u}}$. These parameters are used in updating the student's rank following the pseudo code provided in section 3.2.

\subsection{RESULTS AND DISCUSSION}

\subsection{System Implementation}

The system was developed using MySQL Database Management System (DBMS), PHP as the scripting language and Apache as the web server. Fig.4 presents a student's page. From a student's page, the comments, questions and responses to questions on a selected topic in a course that concerns the student are accessible to him/her. The student can equally make his/her contributions. Each contribution or question asked by a student awaits the course lecturer's rating. The ratings given to contributions and questions are made available to all students in the discussion forum Fig. 5 presents a student's progress bar. This will serve as a motivation for each student using this platform to work harder in order to attain the next higher rank. The course lecturer's page is presented in Fig.6. The course lecturer can visualise contributions from the students and rate them accordingly on a scale of 10 marks. In difficult cases, the lecturer can make his/her contributions to assist the students.

Furthermore, a course lecturer can ascertain students' participations and overall performance of the students on the system. Fig. 7 presents the students' participations information and the rank mix of the students using the course discussion forum..

\subsection{System Testing}

Without any loss of generality, the system was tested with a course in Artificial Intelligence (CPE 512) in the department of Electrical/Electronic and Computer Engineering, University of Uyo, Uyo, and for the testing purpose the constant parameters were set as follows: $\mathrm{Ss}=40, \mathrm{Sm}=60, \mathrm{Se}=80, \mathrm{Sp}=100, \mathrm{Ts}=7200 \mathrm{~s}$ (2hours), $\mathrm{Tm}=10800 \mathrm{~s}$ (3hours), $\mathrm{Te}=14400 \mathrm{~s}$ ( 4 hours) and $\mathrm{Tp}=18000$ s (5hours). Moreover, at the system backend the ranks are assigned numeric values as follows: starter $=1$, senior $=2$, master $=3$, expert $=$ 4 and professional $=5$. The ranking behaviours of selected users with respect to time spent and scores on CPE 512 page have been shown graphically. The graph of Fig.8 presents how the rank of a student with total current score of 92 on CPE 512 page varied with respect to time spent on the course page. From the graph, it can be ascertained that the user rises to the next rank level after the time requirement is satisfied; that is, if he/she reaches the minimum time required to attain that rank. Moreover, the user after attaining the rank of an expert (that is level 4), he/she remained in this rank even though the minimum time for the user to rise to the level of a professional has been exceeded. This is because the user is yet to reach the threshold score for the rank of a professional which is $S_{p}=100$. The variation of this user's rank on CPE 512 with respect to his scores on the course is also shown in Fig.9. It can been observed that as soon as the user meets the minimum score it climbs to the next rank level in as much as the time constraint is satisfied. 


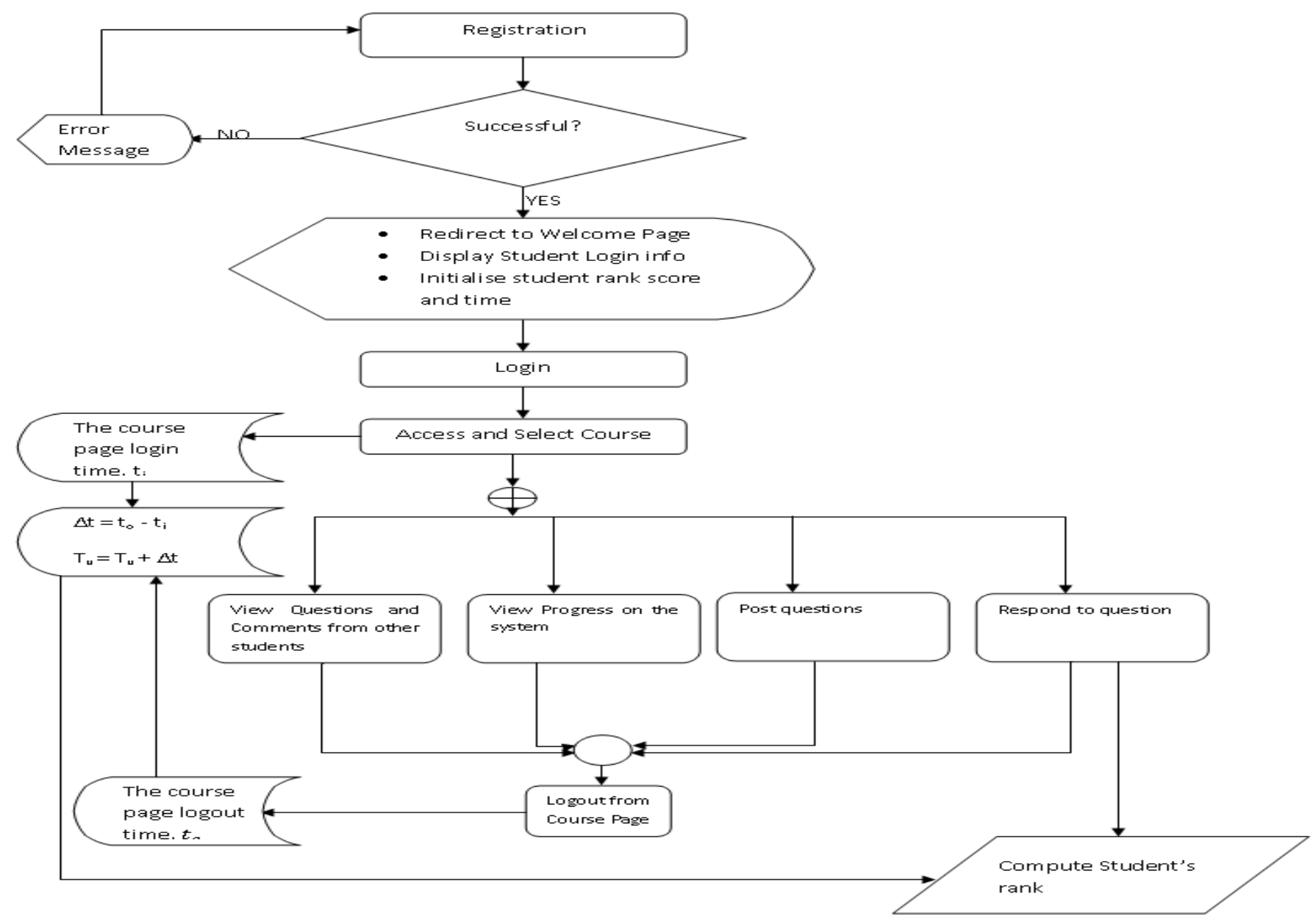

Fig.3: Students Activities Flowchart

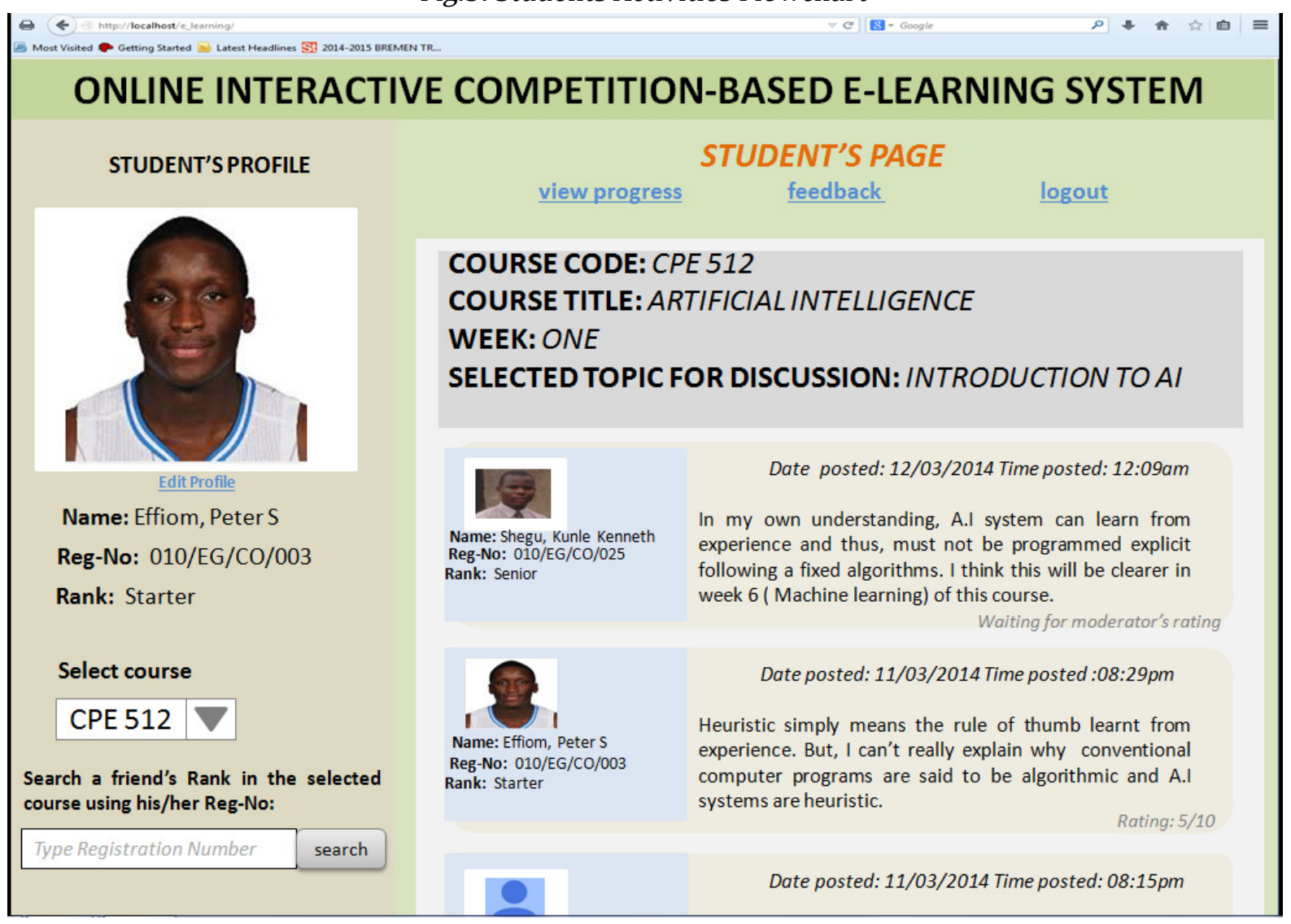

Fig.4: Student's Page 


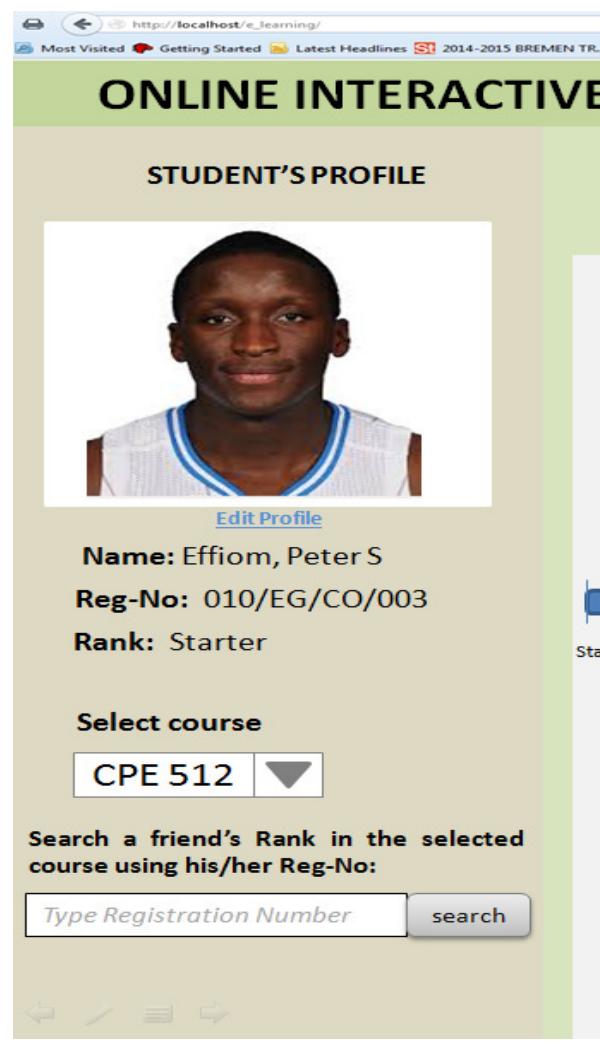

Fig.5: Student Progress page

\section{Student progress}
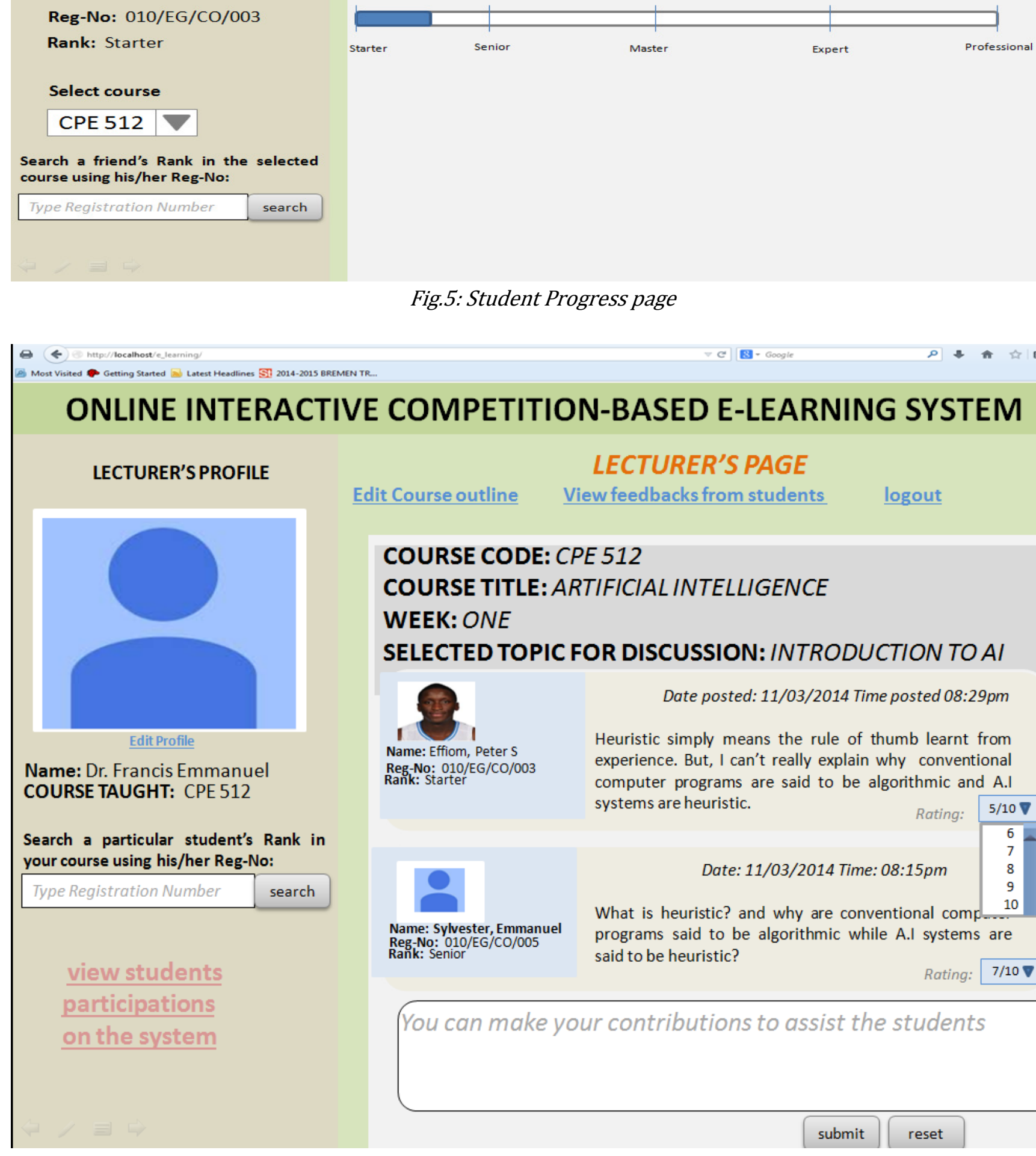

COURSE CODE: $C P E 512$

COURSE TITLE: ARTIFICIAL INTELLIGENCE

WEEK: ONE

SELECTED TOPIC FOR DISCUSSION: INTRODUCTION TO AI

\section{COURSE CODE: CPE 512 \\ COURSE TITLE: ARTIFICIALINTELLIGENCE \\ WEEK: ONE \\ SELECTED TOPIC FOR DISCUSSION: INTRODUCTION TO AI}

\section{LECTURER'S PAGE}

View feedbacks from students

$\underline{\text { logout }}$

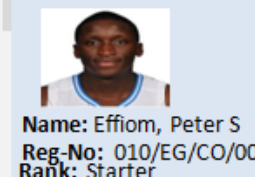

Reg-No: 010/EG/CO/003

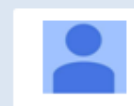

Name: Sylvester, Emmanuel Reg-No: 010/EG/CO/005 Rank: Senior
Date posted: 11/03/2014 Time posted 08:29pm

Heuristic simply means the rule of thumb learnt from experience. But, I can't really explain why conventional computer programs are said to be algorithmic and A.I systems are heuristic.

\section{Date: 11/03/2014 Time: 08:15pm}

What is heuristic? and why are conventional comr 10 programs said to be algorithmic while A.I systems are said to be heuristic?

Rating: $7 / 10 \nabla$

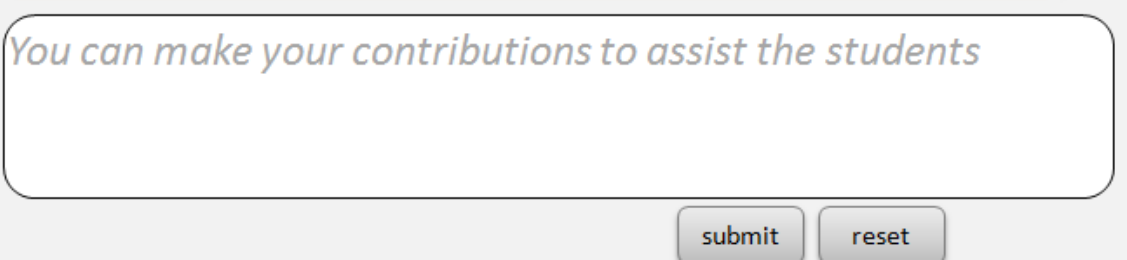

Fig.6: Lecturer's page 


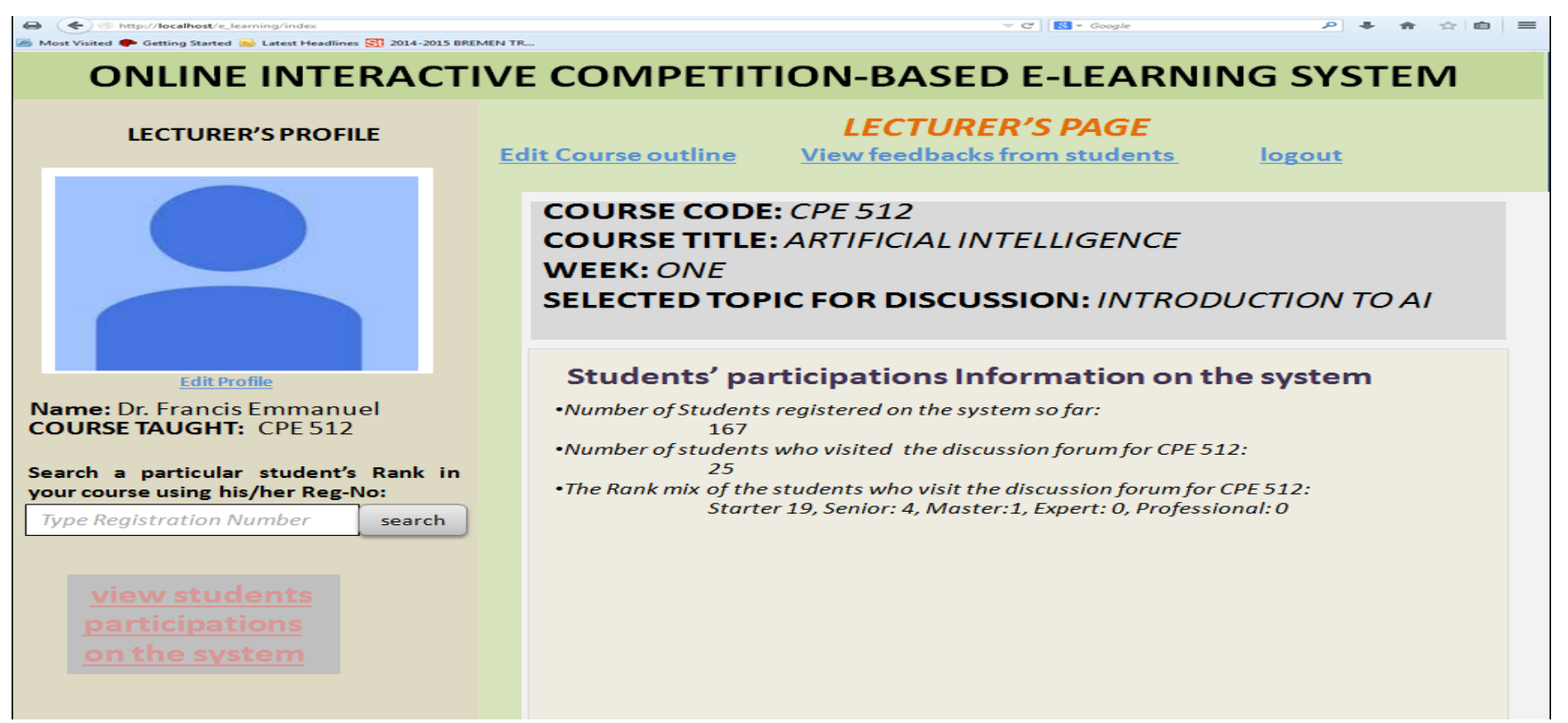

Fig.7: Students' Participation information on the system

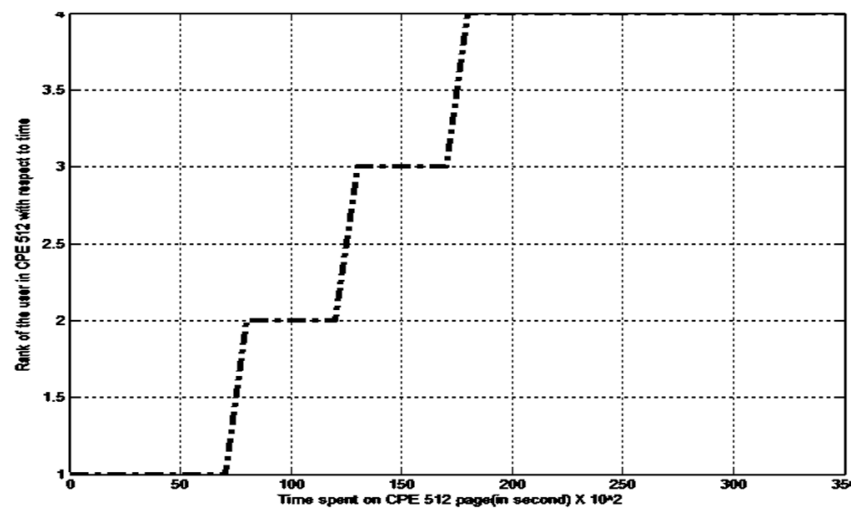

Fig.8: Graph of a student's rank against time spent on CPE 512 (student's current total score $=92$ )

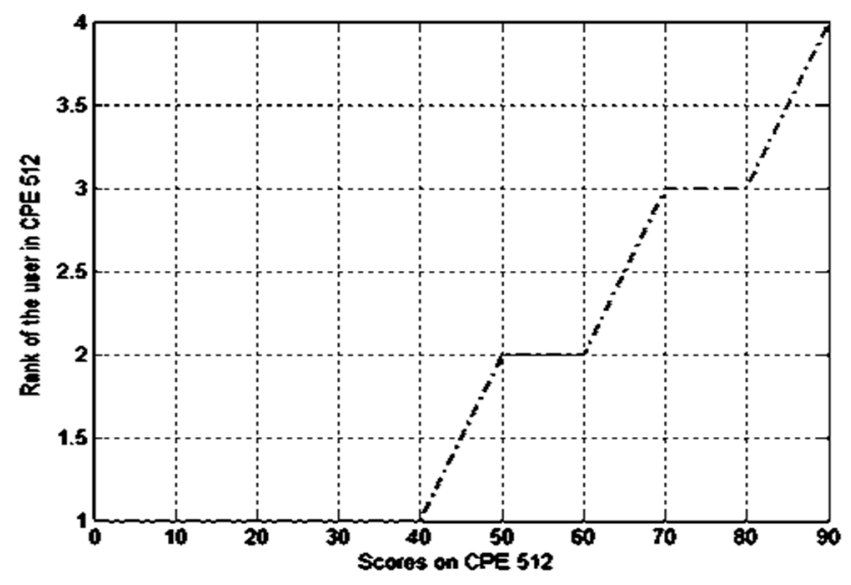

Fig.9: Graph of a student's rank against score on CPE 512

Fig. 10 presents the ranking behaviour of a user who had earned a total current score of 34 after spending a total of 9hours (32400 seconds) on CPE 512 page. The user's rank remained at the level of a starter throughout this period because he has not satisfied the minimum score requirement for a higher rank level even though he/she had met all the time requirements for all the ranks.

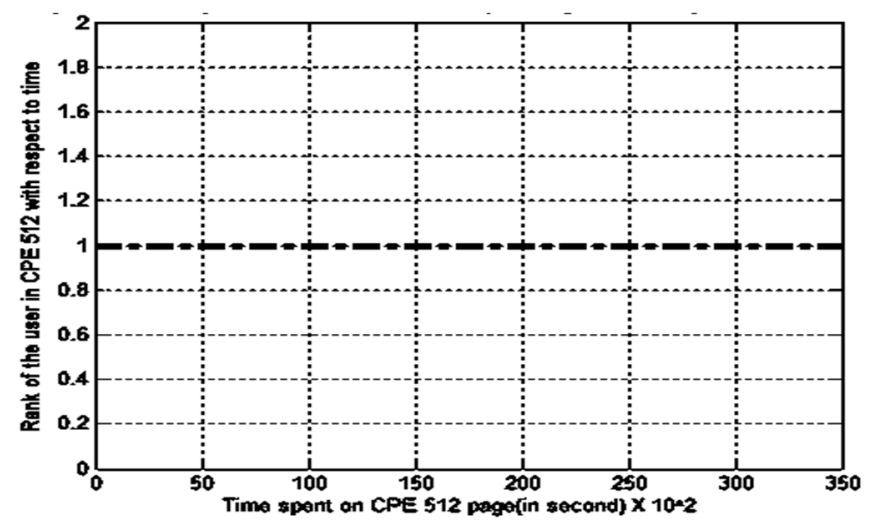

Fig.10: Graph of a student's rank against time spent on CPE 512 (Student's total current score =34)

\section{CONCLUSION}

The thrust of this paper is the integration of competition strategies on an e-learning system. This work was motivated by the undeniable fact that competition can serve as incentive to encourage efficient learning and consequently active participation of students on online learning platforms. As such, Online Interactive Competition Model for E-learning System tailored to incorporate competition on elearning platforms was presented in this paper. The competition strategy used in this system is the ranking of users to different rank levels. These rank levels include starter, senior, master, expert, professional, the starter rank being the initial rank for all registered users in all courses. The ranking algorithm presented in this paper considers users' contributions and the 
total times they spent on a given course page in computing the users' ranks for the course. This system was implemented and tested in order to validate the ranking algorithm and the proposed functionalities of the system. The test results for selected users were shown graphically in this paper.

\section{RECOMMENDATION}

This strategy of incorporating competition on an elearning platform may require synergy with other approaches to achieve a more efficient result. One of such approaches may warrant physical incentives such as money, scholarships, gifts, extra marks and so on, for a well-spelt condition. For example, a student's performance on a course page may reflect on his/her semester result in that course; to be more explicit, a student may be entitled to extra marks in a course if the student can attain the rank of a professional on the course in the first two months of a semester. Hence, the synergy of this strategy with physical incentive is recommended for a more effective outcome.

\section{REFERENCES}

[1] Nicholas, A.E., Ozuomba, S. and Kalu, C. "Community Informatics Social E-Learning Network: A Case Study of Nigeria", Software Engineering, Vol. 1, No. 3, pp. 1321, 2013.

[2] Agbonifo, O. C. "An Online Model for Assessing Students Stepwise Solving Of Calculus Questions",
Nigerian Journal Of Technology (NIJOTECH), Vol. 33. NO. 1, PP. $86-96,2014$.

[3] Ezenkwu, C.P, Ozuomba, S. and kalu, C. "Community Informatics Social Network for Facilitated Community Policing: A Case Study of Nigeria", Software Engineering, Vol. 1, No. 3, pp. 22-30, 2013.

[4] Ivan, C. and Jose, M. C. "Effects of Competition in Education: A Case Study In An E-Learning Environment", Departamento de IngenieríaInformática Universidad Autónoma de Madrid Campus de antoblanco, 28049 Madrid, Spain, 2010.

[5] Chung, C.J. "Learning through Competitions Competition Based Learning (CBL)", LTUCTL Conference poster session, 2008. Available at http://www.robofest.net/LBA/CBL.pdf

[6] Fasli, M. and Michalakopoulos, M. "Supporting Active Learning through Game-like Exercises", In Proceedings of the 5th IEEE International Conference of Advanced Learning Technologies (ICALT), 730734, 2005.

[7] Helen, M." Young People and Technology: A review of the current literature(2nd edition)", The Alannah And Madeline Foundation, 2009.

[8] Sife, A., Lwoga, E. and Sanga, C. "New technologies for teaching and learning: Challenges for higher learning institutions in developing countries", International Journal of Education and Development using ICT, 3(2), 57-67. UWI, 2007. 